\title{
A Comparison of EMG Feedback and Alternative Anxiety Treatment Programs ${ }^{1}$
}

\author{
Bryan A. Hiebert \\ Simon Fraser University \\ George Fitzsimmons \\ University of Alberta
}

Four cohorts of 40 subjects each were randomly assigned to 1 of 10 treatment conditions utilizing EMG feedback, cognitive monitoring training, systematic desensitization, high expectancy discussion group, or waiting list controls either in isolation or in various combinations. A three-way ANOVA for repeated measures indicated that significant anxiety reductions were experienced in all noncontrol treatment conditions. Treatment groups employing EMG feedback demonstrated significantly greater anxiety decrements on Cattell's IPAT Self-Analysis Form, and baseline frontalis EMG. Adding desensitization or cognitive monitoring to EMG feedback did not produce a more powerful effect than using EMG feedback alone. Sex and age differences were also observed. Some implications are discussed.

Anxiety is a central tenet in most theories of psychopathology, and most theories agree that anxiety must be dealt with if therapy is to succeed (Reinking \& Kohl, 1975, p. 595). Some procedures for dealing with anxiety are based on clinical experience and therapist intuition, while other treatment procedures are supported by a research base. Published reports indicate that subjects receiving systematic desensitization (cf. Davison \& Wilson, 1973; Paul, 1969), cognitive modification (Meichenbaum, 1972), stress inoculation training (Meichenbaum, 1975), cognitive monitoring (Hiebert, Note 1), and biofeedback training (Connor, 1974; Grim, 1971;

'This research was supported in part by a grant from the Medical Services Research Foundation of Alberta. 
Townsend, House, \& Addario, 1975) usually experience an anxiety decrement. Some combinations of the above treatment strategies have logical appeal. Budzynski and Stoyva (1973) advocate using EMG feedback with systematic desensitization and cite case studies to support the efficacy of such a combination. Benjamins (1976) used alpha feedback with desensitization in a controlled setting. Recently some authors (Lazarus, 1975; Meichenbaum, 1976) have pointed to cognitive considerations in biofeedback training and have advocated placing biofeedback training within a cognitive context. Although such combined treatments appear reasonable, there has not been much published compartive research to date utilizing biofeedback and other treatment procedures (Blanchard \& Ahles, 1979). A clear need exists for comparative studies investigating such things as differential treatment effects, treatment economy, and duration of effect (Blanchard \& Ahles, 1979; Gelder, 1979), and for comparing "newer" treatment procedures with more established or "best available" alternatives.

In this study three anxiety treatment procedures are investigated: cognitive self-monitoring, systematic desensitization, and frontal EMG biofeedback training. The treatment procedures were used in isolation and in various combinations. High expectancy discussion groups (placebo) and waiting list controls were incorporated in the study in an endeavor to control for nonspecified effects. The main components of each treatment program are outlined below.

EMG Feedback. The decision to use EMG feedback in an anxiety treatment program has logical appeal because muscle relaxation has long been considered incompatible with anxiety (Grossberg \& Wilson, 1968; Luthe, 1972; Wolpe, 1958, 1969). The authors recognize the controversy surrounding the use of frontal EMG as an indicator of general relaxation (cf. Alexander, 1975); however, Alexander (1975) can be criticized on methodological grounds, frontal EMG is probably the most commonly used relaxation training procedure, and there is an abundant literature supporting the use of frontal EMG for relaxation training (Budzynski, 1973; Budzynski \& Stoyva, 1973; Leaf \& Gaarder, 1971; Reinking \& Kohl, 1975; Stoyva \& Budzynski, 1975). In this study, six EMG training sessions of 20 minutes' duration were used.

A three-stage training model was used (cf. Budzynski, 1973; Meichenbaum, 1976), initially focusing on increasing awareness of muscle tension, then developing a strategy for controlling muscle tension levels, and finally demonstrating willful control of muscle tension in the absence of external feedback.

Cognitive Monitoring. Hiebert (Note 1) demonstrated that people taught to cognitively self-monitor their anxiety level experienced an anxiety decrement that was maintained over time. The procedure involved teaching people to use Wolpe's (1969) notion of Subjective Units of 
Disturbance (SUDS) to acquire the facility for monitoring anxiety on an ongoing basis: to develop, as it were, a mental speedometer that could track anxiety, thus providing people with ongoing feedback about their anxiety level. Initially, subjects were instructed to develop a Subjective Anxiety Scale, ranging from 0 to 100 , with the numbers representing subjective units of disturbance (SUDS). To develop a SUDS scale, subjects were asked to label various anxiety-evoking situations with respect to the amount of disturbance (i.e., the number of SUDS) they evoked. The situation that produces the most anxiety for an individual was labeled 100 SUDS; a situation in which a person feels no anxiety was labeled 0 SUDS. All other situations that a person can experience must fit between these two extremes (Wolpe, 1969, 1976).

After devleoping their own subjective anxiety scale, subjects were instructed to monitor their SUDS levels at hourly intervals between treatment sessions, and to record the time, situations, and SUDS level in a small pocket notebook. The purpose of the notebook was to help subjects remember to do the monitoring and to provide a means for checking to make sure the monitoring was done. It seemed to the authors that the SUDS monitoring training process might parallel at least part of the biofeedback training process, except that SUDS monitoring occurred at a strictly cognitive (non-machine-mediated) level.

Systematic Desensitizatin. Systematic desensitization is perhaps the most widely researched anxiety treatment procedure (cf. Davison \& Wilson, 1973; Franks \& Wilson, 1974; Paul, 1969; Tryon, 1980). Although the mechanism underlying desensitization has been called into question (cf. Davison \& Wilson, 1973), one fact remains unchallenged: Systematic desensitization works. The common theme throughout substantial reviews of the literature (e.g., Davison \& Wilson, 1973; Franks \& Wilson, 1974; Paul, 1969; Wolpe, Brady, Serber, Agras, \& Liberman, 1973) is that systematic desensitization has a high probability for success when applied to the treatment of appropriate anxieties. Furthermore, Wolpe et al. (1973) emphasize that therapists must constantly monitor the felt and observed muscle tension in their patients during desensitization. The implied role of EMG feedback or cognitive monitoring in Wolpe's statment is obvious. However, since the initial work of Budzynski and Stoyva (1973), no controlled studies using EMG biofeedback and systematic desensitization have emerged.

\section{THE PROBLEM}

To date, most of the investigations into biofeedback anxiety control procedures have been concerned with the demonstration of an effect. Once 
a treatment effect had been demonstrated, concern was expressed over expectancy variables and the lack of systematic controlled investigations (Blanchard \& Young, 1974; DiCara, 1975; Melzak, 1975). Recently, appeals have been made for research comparing biofeedback to established clinical procedures (Miller, 1978). It was these considerations that gave rise to the present investigation.

Specifically, the present study examined the relative efficacy of EMG biofeedback training, cognitive monitoring training, systematic desensitization and EMG-augmented desensitization. It was also thought that the framework provided by cognitive monitoring training might facilitate EMG biofeedback training. High expectancy, discussion group, and waiting list controls were included in the design to control for expectancy variables and transient temporal factors.

\section{METHOD}

\section{Research Design}

The research design used in this study was a two-stage, four-group, repeated-measures design with an added nonorthogonal control group (see Table I). During stage 1 the primary emphasis was on awareness of anxiety. In stage 2, subjects either continued with the treatment format commenced in stage 1 or entered a habit substitution condition incorporating systematic desensitization.

Table I. Schedule for Testing and Treatment ${ }^{a}$

\begin{tabular}{|c|c|c|}
\hline \multicolumn{2}{|c|}{$\begin{array}{l}\text { Group number } \\
\text { (Factor A) }\end{array}$} & \multirow{2}{*}{ 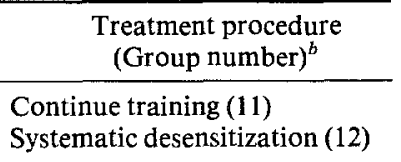 } \\
\hline 1 & $\begin{array}{l}\text { EMG biofeedback } \\
\text { training }\end{array}$ & \\
\hline 2 & $\begin{array}{l}\text { Cognitive } \\
\text { monitoring }\end{array}$ & $\begin{array}{l}\text { Continue monitoring (21) } \\
\text { Systematic desensitization (22) }\end{array}$ \\
\hline 3 & $\begin{array}{l}\text { EMG biofeedback } \\
\text { training and } \\
\text { cognitive monitoring }\end{array}$ & $\begin{array}{l}\text { Continue monitoring (31) } \\
\text { Systematic desensitization (32) }\end{array}$ \\
\hline 4 & $\begin{array}{l}\text { High expectancy } \\
\text { discussion group }\end{array}$ & $\begin{array}{l}\text { Continue placebo interaction (41) } \\
\text { Systematic desensitization (42) }\end{array}$ \\
\hline 5 & $\begin{array}{l}\text { Waiting list } \\
\text { control }\end{array}$ & $\begin{array}{r}\text { Continue no contact (51) } \\
(52)\end{array}$ \\
\hline
\end{tabular}

${ }^{a}$ Anxiety measures were administered at $T_{1}, T_{2}$, and $T_{3}$.

${ }^{b}$ The group number in parentheses is used to identify treatment procedures in subsequent pages of this paper. 
Dependent Measures. Two dependent measures were used: the IPAT Self-Analysis Form (Cattell, 1957) and a 5-minute frontal EMG baseline.

The IPAT is a 40-item scale designed to assess a person's current perception of his/her manifest anxiety level, whether it is situationally determined or relatively independent of the immediate situation (Cattell \& Scheier, 1963). The IPAT was used primarily because it correlates highly with physiological measures (Cohen, 1965; Smith, 1973). EMG data were obtined in the usual manner adopted in biofeedback research (Budzynski, 1973; Townsend et al., 1975). After the attachment of surface electrodes to the frontal region, subjects were told to relax as much as possible, using whatever strategy they usually used to relax. Subjects were given about 30 seconds to settle themselves, then EMG recording was begun. Ten-second average microvolt levels were recorded over a 5-minute baseline period. Both dependent measures were administered on the same days across all treatment conditions-at the beginning of session 1, again at the beginning of session 3 (commencing stage 2), and again during session 6 , as a posttest (see Table I).

All treatment subjects (groups 1-4) received six 50-minute treatment sessions. Waiting list control subjects (group 5) were told that it was necessary to obtain a stable indication of their anxiety level before treatment could begin. These subjects completed all dependent measures on the same days as subjects assigned to treatment conditions. After the three assessments referred to above, waiting list control subjects were assigned to biofeedback practicum students for treatment. All treatment programs were conducted in groups of four. Therefore, at any one time there were 40 subjects in the study. When one group of 40 subjects (a cohort) finished their respective treatment programs there would be a 1-week break, after which another group of 40 subjects (cohort) would commence treatment.

A random sampling of subjects from each cohort were contacted 1 month after treatment completion, for follow-up purposes.

\section{Equipment and Facilities}

All sessions were carried out in a standard 10 foot $\times 16$ foot laboratory. Subjects sat on comfortable lounge chairs, the experimenter sat in a chair facing the subjects, and the research assistant sat at a table adjacent to the experimenter. All EMG units were housed on bookshelves behind the subjects. The data acquisition equipment was on the table in front of the research assistant.

All EMG levels were measured using an Autogenics Systems Inc. 1700 electromyograph. Each subject had his/her own EMG. A 1-second response averaging mode was used in generating the feedback signal, and a 100- to $200-\mathrm{Hz}$ band pass was used, as recommended by the manufacturer. The muscle 
tension information from all four subjects was processed simultaneously using the Autogenics Systems Inc. 5600 data acquisition center and printer assembly. Research grade electrodes were applied in the standard manner for measuring frontal EMG (cf. Budzynski, 1973) and impedances of 10,000 ohms or less were maintained throughout.

\section{Subjects}

Subjects were obtained from announcements in the local media and large undergraduate classes, inviting participation in an anxiety control project. A press release was issued through the university public relations department stating that there was a project comparing different anxiety control procedures being conducted at the University of Alberta and listing the telephone number to call if people wished to participate. The class announcements consisted of an abbreviated form of this press release.

Of the 173 subjects commencing the project, 162 completed their respective treatment programs. This represents a $6.36 \%$ dropout rate. Subject's ages ranged from 16 to 62, with a mean age of 29.4 years. About $69 \%$ of the sample were students, predominantly from the faculties of education, arts, and science; the remainder were mostly businesspersons. There were 56 men and 104 women. About $23 \%$ of the sample had interacted at some time with either a psychiatrist or a psychologist concerning their anxiety. Although $43 \%$ of the sample labeled their own anxiety level as high, initial screening indicated that there were no persons exhibiting pathological levels of anxiety. Thus, the anxiety experienced by these subjects is likely best described as similar to the anxiety experienced by many "normal" people-not debilitating but often interfering with optimal functioning and serious enough to seek assistance if a nonthreatening opportunity arose to do so.

\section{Therapist}

The senior author, a certified psychologist, acted as the therapist for all groups. He was assisted by a master's-level counseling student who was responsible for EMG recording, administering the dependent measures, and assisting with skin preparation and sensor application. Procedures were incorporated to control for therapist equivalence across treatment groups (cf. Shaw, 1976). These procedures are elaborated in the Results section of this paper. 


\section{Procedure}

Two subjects were dropped from the sample when equipment failure resulted in incomplete baseline data. The remaining 160 subjects were randomly assigned to the five treatment conditions in stage 1 , yielding 32 persons in each group. All treatment conditions began with the pretest, described earlier, followed by a discussion of the conceptual nature of anxiety emphasizing the learned, habitual aspects of anxiety, the muscle tension correlates of anxiety reactions, and the role that relaxation can play as an anxiety inhibitor. All subjects in EMG feedback conditions received six training sessions of 20 minutes each. Three segments of frontal EMG activity (90 seconds each) were recorded at the beginning, middle, and end of the training sessions. The remaining 30 minutes of each treatment session were spent in electrode application, debriefing after training, and discussing homework and/or transfer considerations.

Stage 1 of Treatment. In the first two sessions, subjects in group 1 focused on body awareness, exploring control strategies and identifying subjective feeling indicators accompanying slow clicking rates. Subjects in group 2 received instruction and practice in using Wolpe's (1969) notion of subjective units of disturbance (SUDS) to cognitively self-monitor anxiety level (cf. Hiebert, note 1) in the manner outlined earlier in this paper. Subjects in group 3 received EMG feedback within the context of cognitive monitoring. The purpose of this combination was to promote transfer outside the laboratory setting and to see whether or not a self-monitoring framework enhanced biofeedback training. The agenda for group 4 was developed in consultation with faculty members adhering to an existential perspective. The discussion focused on underlying value systems and belief pattern, issues of self-autonomy and other-directedness, and a person's sense of general well-being and self-directedness that lay at the heart of anxiety reactions. The notion was developed that the way to achieve real, lasting relief from anxiety was to focus on these underlying causes rather than "merely treating the symptoms of anxiety." Thus, group 4 functined as a high expectancy (or placebo) control group. No contact controls were told it was necessary to obtain a stable indication of anxiety level on three occasions roughly a week apart. These assessments coincided with the assessment times for the treatment groups.

Stage 2 of Treatment. Session 3 began with the administration of the three dependent measures, after which subjects were assigned to continuation of initial treatment or systematic desensitization conditions. Desensitization subjects (groups 12, 22, 32, 42) received one session of orientation and individual hierarchy construction, followed by three desensitization sessions. 
In sessions 4 to 6 , biofeedback-only subjects (group 11) focused on identifying feeling states and control cues accompanying or precipitating a decrease in click rate. Transfer considerations were then addressed. Subjects practiced willfully decreasing muscle tension without the aid of EMG feedback and were given instruction in implementing relaxation responses prior to anticipated stressors. Cognitive monitoring subjects (group 21) focused on becoming more aware of small changes in anxiety level at the low end of the arousal continuum. In addition they were instructed to identify personal strategies that were successful in maintaining a low anxiety profile. Subjects in the combination group (group 31) continued EMG feedback training augmented by a SUDS monitoring program to aid in perceiving increases in anxiety level and relaxing them away. Group 4 subjects (group 41) continued to discuss basic belief systems, role conflicts, self-confidence issues, and personal values that lay at the root of anxiety reactions.

\section{RESULTS}

\section{Specific Findings}

Group IPAT means and EMG levels are presented in Table II. These data were analyzed using a two-way ANOVA for repeated measures and Scheffé multiple comparisons where appropriate. A significant times effect $(p \leq .05)$ in IPAT and EMG baseline data indicated that regardless of treatment condition, subjects generally experienced an anxiety decrement during the course treatment. However, significant $\mathrm{A} \times \mathrm{C}$ interactions

Table II. Mean IPAT Scores and EMG Baseline Levels for 160 Subjects

\begin{tabular}{|c|c|c|c|c|c|c|c|}
\hline \multirow{2}{*}{\multicolumn{2}{|c|}{$\begin{array}{l}\text { Treatment } \\
\text { group }\end{array}$}} & \multicolumn{6}{|c|}{ Times } \\
\hline & & \multicolumn{2}{|c|}{1} & \multicolumn{2}{|c|}{2} & \multicolumn{2}{|c|}{3} \\
\hline A & B & IPAT & EMG & IPAT & EMG & IPAT & $\mathrm{EMG}$ \\
\hline 1 & 1 & 41.188 & 1.720 & 37.500 & 1.495 & 32.875 & 1.200 \\
\hline 1 & 2 & 39.563 & 2.221 & 38.750 & 1.730 & 35.875 & 1.426 \\
\hline 2 & 1 & 35.938 & 2.147 & 32.188 & 1.878 & 29.000 & 1.415 \\
\hline 2 & 2 & 43.750 & 2.397 & 41.125 & 2.291 & 34.000 & 2.247 \\
\hline 3 & 1 & 43.438 & 1.898 & 40.438 & 2.056 & 34.250 & 1.433 \\
\hline 3 & 2 & 48.063 & 2.445 & 42.563 & 1.689 & 39.938 & 1.357 \\
\hline 4 & 1 & 34.375 & 2.001 & 31.625 & 1.858 & 25.500 & 1.737 \\
\hline 4 & 2 & 38.875 & 1.535 & 39.625 & 1.577 & 37.750 & 1.440 \\
\hline 5 & 1 & 39.000 & 2.158 & 39.813 & 2.157 & 38.938 & 1.968 \\
\hline 5 & 2 & 41.625 & 1.915 & 43.750 & 2.083 & 43.500 & 1.872 \\
\hline
\end{tabular}




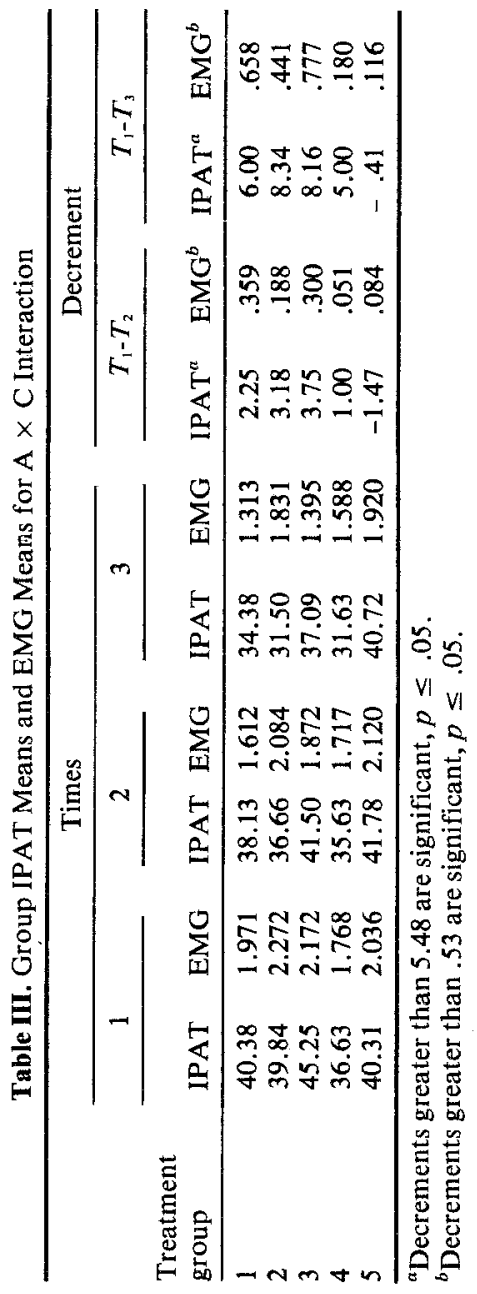


indicated a differential reduction in anxiety level across time for the five treatment groups. (The A $\times \mathrm{C}$ IPAT and EMG means are presented in Table III.)

A Scheffe multiple-comparisons procedure was used to determine the critical anxiety decrement for $p \leq .05$ (cf. Winer, 1962). Significant IPAT decrements were found in groups 1,2, and 3, but not in groups 4 and 5 , $\operatorname{Sch}(8,300) \geq 15.51, p \leq .05$. Significant EMG decrements were observed in groups 1 and 3 , but not in groups 2,4 , or $5, \operatorname{Sch}(8,300) \geq 15.68$, $p \leq .05$. These data suggest that EMG biofeedback training and cognitive self-monitoring training are both more effective in reducing self-reported anxiety, as measured by the IPAT, than a discussion-oriented therapeutic approach, and that an EMG biofeedback training program is more effective in reducing muscle tension than either a cognitive monitoring or a discussion aproach.

Combined Treatment Programs. Combining EMG biofeedback with other therapeutic procedures did not enhance the effect gained from using EMG biofeedback alone. Although cognitive monitoring subjects demonstrated an anxiety decrease, placing biofeedback training within this cognitive context was not more effective than using a traditional EMG biofeedback approach. Adding systematic desensitization to the EMG biofeedback program did not prove more facilitative. Groups receiving EMG-augmented desensitization (groups 12 and 32) did demonstrate significant EMG decrements; however, the significant decrease took place prior to the onset of desensitization: Systematic desensitization seemed to add little to the effect already obtained. (See Table II for the group EMG means. Within-row differences greater than .46 are significant, $\operatorname{Sch}(2,300) \geq 6.06, p \leq .05$.)

\section{Demographic Differences}

When an investigation utilizes a wide demographic range of subjects, the question naturally arises as to whether certain types of people are more responsive to treatment. In an attempt to address this question, a post hoc analysis of the demographic variables was conducted. Several two-way ANOVAS for repeated measures (demographic variable $\times$ time) were utilized in an attempt to uncover differential treatment effects within the demographic categories recorded in this study. The significant findings are reported below.

Age. Significant differences were observed in muscle tension decrements across time for different age categories. (See Table IV for mean EMG levels.) These differences were not reflected in the IPAT scores.

Scheffe multiple comparisons indicated that significant EMG decrements were experienced in the 25 years and younger, the 30-39 years, 
Table IV. Mean EMG Levels for Age (Factor A) Across Time (Factor B), $N=$ 160

\begin{tabular}{lrrcc}
\hline & \multicolumn{4}{c}{ Test time } \\
\cline { 2 - 5 } Age & \multicolumn{1}{c}{$N$} & 1 & 2 & 3 \\
\hline $20-$ & 30 & 1.863 & 1.467 & 1.296 \\
$21-24$ & 41 & 1.734 & 1.481 & 1.188 \\
$25-29$ & 29 & 1.693 & 1.702 & 1.486 \\
$30-39$ & 33 & 2.662 & 2.551 & 2.164 \\
$40-49$ & 20 & 2.011 & 2.255 & 1.908 \\
$50+$ & 7 & 2.865 & 2.117 & 2.021 \\
\hline
\end{tabular}

and the 50 years and over age categories, $\operatorname{Sch}(2,308) \geq 6.06, p \leq .05$. Significant differences were also evident in initial baseline EMG levels. The 30-39 years and the 50 years and over age categories had significantly higher EMG levels than those whose age was 29 years and younger, $S c h(5,462) \leq 11.15, p \geq .05$. Upon completion of treatment, significant differences in EMG level were still observed between 30- to 39-year-olds and those 25 years and younger, $\operatorname{Sch}(5,462) \geq 11.15, p \leq .05$; other differences were no longer significant.

Generally speaking, younger subjects ( 29 and under) demonstrated lower muscle tension than older subjects (ages 30-39 and 50 or more). Additionally, younger subjects ( 25 and under), older subjects ( 50 and over), and subjects aged 30-39 demonstrated greater muscle tension decrements during treatment than subjects ages 25-29 and 40-49.

Sex. Significant male-female differences were observed in IPAT scores and EMG levels (see Table $\mathrm{V}$ for the means). The ANOVAS indicated significant between-groups differences in both the IPAT, $F(1,158)$ $=6.86, p \leq .01$, and EMG, $F(1,158)=14.4, p \leq .01$, data. Pretest scores suggested that this effect might be due primarily to initial differences in anxiety level. An analysis of covariance was used to check out this suspicion. The analysis of covariance produced no significant differences in IPAT posttest scores covaried over pretest; however, there were still

Table V. Mean Scores for Sex (Factor A) Across Time (Factor B), $N=160$

\begin{tabular}{llrccc}
\hline & & & \multicolumn{3}{c}{ Test time } \\
\cline { 3 - 6 } Variable & Sex & $N$ & 1 & 2 & 3 \\
\hline IPAT & Male & 56 & 37.37 & 35.40 & 32.88 \\
& Female & 104 & 42.20 & 40.58 & 37.24 \\
EMG & Male & 56 & 1.760 & 1.530 & 1.284 \\
& Female & 104 & 2.201 & 2.076 & 1.790 \\
\hline
\end{tabular}


significant differences in adjusted posttest EMG levels, $F(1,157)=7.34$, $p \leq .01$.

The above findings suggest that male subjects had lower initial EMG levels than female subjects, and experienced greater decreases in muscle tension levels during the course of treatment.

The pattern in these data is not clear enough to warrent making strong statements regarding treatment propensity. However, one might tentatively suggest, in general, that resting frontal EMG increases with age of subject, that females have higher EMG than males, and that for the treatments used in this study, males and people outside of the 40-49 age range responded most readily to treatment. One hopes that further research designed to address directly the aptitude-treatment interaction question in anxiety control and biofeedback training will provide a more conclusive result.

\section{Therapist Effects}

In this study all treatment programs were conducted by the same therapist. In order to determine therapist equivalence and perceived treatment effectiveness across groups, all subjects were asked to rate therapist characteristics (competence, likableness, understanding, genuineness) and treatment characteristics (meaningfulness, effectiveness) at the conclusion of treatment (cf. Shaw, 1976). This rating scale was administered by the research assistant (therapist absent) during the final session. A Kruskal-Wallis one-way analysis of variance by ranks indicated no significant between-groups differences in perceived therapist characteristics or perceived treatment effectiveness. Therefore, it seems unlikely that the differences in anxiety decrements across treatment groups is a function of therapist variables.

\section{Follow-Up Data}

In order to obtain an indication of treatment permanence, a random sampling of treatment subjects from each cohort was contacted by telephone about 1 month after posttesting. The subjects were told that a follow-up contact was being made and were asked two questions: (a) Have you noticed any changes in your anxiety since the research project finished? and (b) Was it your initial impression that the program helped reduce your anxiety or did it really not help that much? The responses to these questions are reported in Table VI. These results were analyzed using a chi-square test of independence. A significant relationship was found between the initial impression of treatment effectiveness and the maintenance of the treatment 
Table VI. Summary of Follow-Up Responses

\begin{tabular}{lccc}
\hline & \multicolumn{2}{c}{ Treatment effect } & \\
\cline { 2 - 3 } Initial & & & \\
impression & Reduced anxiety & No change & Total \\
\hline Yes, it helped & 29 & 5 & 34 \\
No, not really & 7 & 5 & 12 \\
$\quad$ Total & 36 & 10 & 46 \\
\hline
\end{tabular}

effect, $\chi^{2}=3.79, p \leq .05$. When the results are analyzed according to perceived benefit of treatment 1 month following treatment termination, $73.9 \%$ of the subjects in the follow-up sample reported substantially less anxiety. These perceptions of reduced anxiety correlated highly with actual EMG change.

\section{Summary}

The above data suggest that all treatment programs appeared to be working in the experimental setting: Subjects demonstrated anxiety reductions regardless of treatment condition. Treatment groups employing EMG feedback demonstrated more consistent reductions on both dependent measures. Groups in cognitive monitoring training and systematic desensitization conditions demonstrated significant anxiety decrements; however, combining either of these treatment procedures with EMG feedback did not produce a more powerful effect than using EMG feedback alone. Subjects in the high expectancy discussion group experienced smaller IPAT and EMG reductions than other treatment subjects. Some demographic differences were found: Males responded more favorably to treatment than females and some age differences were also observed.

Thus, it would appear that EMG feedback focusing on awareness and control of muscle tension is at least as effective in producing anxiety decreases (EMG and IPAT) as some traditional procedures. Combining traditional anxiety treatment procedures with EMG feedback is unlikely to enhance the anxiety decrements obtained from using EMG feedback alone. Using EMG biofeedback to develop increased awareness of change in muscle tension levels and to cultivate a skill in willfully relaxing muscle tension appears to be sufficient to produce significant anxiety decreases without the use of adjunctive procedures. Most subject in this study were able to apply these skills to specific environmental stressors without a specific program aimed at substituting relaxation habits for anxiety habits. 


\section{DISCUSSION}

Miller (1978) outlines three sequential phases for evaluating treatment: (a) pilot studies, anecdotal case reports, systematic case studies, or uncontrolled single group studies to establish the existence of a treatment effect; (b) controlled comparisons with the best available other treatment techniques; and finally (c) broad clinical trials with large samples under the conditions to be expected in general use. The study outlined above represents a controlled comparison between EMG biofeedback and some of these "best available alternatives." If these results are replicated in other laboratories, then a substantial contribution to the research in this area will have been made.

Some implications for future research are clear. Bronfenbrenner (1976), Goldman (1976), and Barrios and Shigetomi (1979) all advocate the ultimate testing of clinical procedures under conditions that closely approximate clinical settings. In the present study, the random assignment to treatment conditions resulted in certain subjects receiving a treatment that was not optimally suited to their present problem (e.g., subjects receiving desensitization who had no clear anxiety focus). Moreover, because therapist contact time was held constant across groups and some subjects learn more quickly than others, not all subjects achieved adequate control over muscle tension. Both of these conditions would seldom occur in a clinical setting. Having an independent diagnostician assign subjects to treatment conditions on the basis of a priori criteria and having subjects train to predetermined criterion levels in EMG conditions would more closely approach clinical conditions.

Research in these or similar directions would undoubtedly enhance the knowledge pool concerning the clinical applications of biofeedback training.

\section{REFERENCE NOTE}

1. Hiebert, B. A. Cognitive monitoring of anxiety as a therapeutic aid. Paper presented at the Thirty-eighth Annual Meeting of the Canadian Psychological Association, Vancouver, June 1977.

\section{REFERENCES}

Alexander, A. B. An experimental test of assumptions relating to the use of electromyographic biofeedback as a general relaxation technique. Psychophysiology, 1975, 12, 656-662.

Barrios, B. A., \& Shigetomi, C. C. Coping skills training for the management of anxiety: A critical review. Behavior Therapy, 1979, 10, 472-522.

Benjamins, $\mathbf{J}$. The effectiveness of alpha feedback training and muscle relaxation procedures in systematic desensitization. Biofeedback and Self-Regulation, 1976, 1, 352. (Abstract) 
Blanchard, E. B., \& Ahles, T. A. Behavioral treatment of psychophysical disorders. Behavior Modification, 1979, 3, 518-549.

Blanchard, E. B., \& Young, L. D. Clinical applications of biofeedback training: A review of evidence. Archives of General Psychiatry, 1974, 30, 573-589.

Bronfenbrenner, U. The experimental ecology of education. Educational Researcher, 1976, 5, 5-15.

Budzynski, T. H. Biofeedback procedures in the clinic. In L. Birk (Ed.), Behavioral medicine. New York: Grune and Stratton, 1973.

Budzynski, T. H., \& Stoyva, J. Biofeedback techniques in behavior therapy. In D. Shapiro, T. X. Barber, L. V. DiCara, J. Kamiya, N. E. Miller, \& J. Stoyva (Eds.), Biofeedback and self-control 1972. Chicago: Aldine, 1973.

Cattell, R. B. Self-analysis form. Champaign, Illinois: IPAT, 1957.

Cattell, R. B., \& Scheier, I. H. Handbook for the IPAT anxiety scale questionnaire (self-analysis form). Champaign, Illinois: IPAT, 1963.

Cohen, J. The IPAT anxiety scale. In O. Buros (Ed.), The sixth mental measurements yearbook. Highland Park, Illinois: Gryphon, 1965.

Connor, W. H. Effects of brief relaxation training on autonomic response to anxiety-evoking stimuli. Psychophysiology, 1974, II, 591-599.

Davison, G. G., \& Wilson, G. T. Process of fear reduction in systematic desensitization: Cognitive and social reinforcement factors in humans. Behavior Therapy, 1973, 4, 1-21.

DiCara, L. Introduction. In L. DiCara, T. X. Barber, J. Kamiya, N. E. Miller, D. Shapiro, \& J. Stoyva (Eds.), Biofeedback and self-control 1974. Chicago: Aldine, 1975.

Franks, C. M., \& Wilson, G. T. Flooding, modeling and behavior reversal. In C. M. Franks \& G. T. Wilson (Eds.), Annual review of behavior therapy: Theory and practice 1974. New York: Brunner/Mazel, 1974.

Gelder, M. Behavior therapy for neurotic disorders. Behavior Modification, 1979, 3, 469-495.

Goldman, L. A revolution in counseling research. Journal of Conseling Psychology, 1976, 23, 543-552.

Grim, P. Anxiety change produced by self-induced muscle tension and by relaxation with respiration feedback. Behavior Therapy, 1971, 2, 11-17.

Grossberg, J. M., \& Wilson, H. K. Physiological changes accompanying the visualization of fearful and neutral situations. Journal of Personality and Social Psychology, 1968, 10, 124-133.

Lazarus, R. S. Cognitive and coping processes in emotion. In B. Weiner (Ed.), Cognitive views of human motivation. New York: Academic, 1974.

Lazarus, R. S. A cognitively oriented psychologist looks at biofeedback. American Psychologist, $1975,30,553-561$.

Leaf, W. B., \& Gaarder, K. R. A simplified electromyographic feedback apparatus for relaxation training. Journal of Behavior Therapy and Experimental Psychiatry, 1971, 2, $39-43$.

Luthe, W. Autogenic therapy: Excerpts on applicatins to cardiovascular disorders and hypercholesteremia. In J. Stoyva, T. X. Barber, L. V. DiCara, J. Kamiya, N. E. Miller, \& D. Shapiro (Eds.), Biofeedback and self-control 1971. Chicago: Aldine, 1972.

Meichenbaum, D. Cognitive modification of test anxious college students. Journal of Consulting and Clinical Psychology, 1972, 39, 370-380.

Meichenbaum, D. A self-instructional approach to stress management: A proposal for stress inoculation training. In C. D. Spielberger \& I. G. Sarason (Eds.), Stress and anxiety. New York: Wiley, 1975.

Meichenbaum, D. Cognitive factors in biofeedback therapy. Biofeedback and Self-Regulation, 1976, 1, 201-216.

Melzak, R. The promise of biofeedback-Don't hold the party yet. Psychology Today, 1975, $9(2), 18-22$.

Miller, N. E. Biofeedback and visual learning. Annual Review of Psychology, 1978, 29, 373-404.

Paul, G. L. Outcome of systematic desensitization. In C. M. Franks (Ed.), Behavior therapy: Appraisal and status. New York: McGraw-Hill, 1969.

Reinking, R. H., \& Kohl, M. L. Effects of various forms of relaxation training on physiological and self-report measures of relaxation. Journal of Consulting and Clinical Psychology, $1975,43,595-600$. 
Shaw, B. F. Comparison of cognitive therapy and behavior therapy in the treatment of depression. Journal of Consulting and Clinical Psychology, 1976, 45, 543-551.

Smith, R. P. Frontalis muscle tension and personality. Psychophysiology, 1973, 10, 311-312.

Stoyva, J., \& Budzynski, T. H. Cultivated low arousal-An antistress response. In L. V. DiCara, T. X. Barber, J. Kamiya, N. E. Miller, D. Shapiro, \& J. Stoyva (Eds.), Biofeedback and self-control 1974. Chicago: Aldine, 1975.

Townsend, R. E., House, J. F., \& Addario, P. A comparison of biofeedback-mediated relaxation and group therapy in the treatment of chronic anxiety. American Journal of Psychiatry, 1975, 132, 589-601.

Tryon, G. S. The measurement and treatment of test anxiety. Review of Educational Research, $1980,50,343-372$.

Winer, J. B. Statistical principles in experimental design (2nd ed.). New York: McGraw-Hill, 1962.

Wolpe, J. Psychotherapy by reciprocal inhibition. Stanford: Stanford University Press, 1958.

Wolpe, J. The practice of behavior therapy (1st ed.). New York: Pergamon, 1969.

Wolpe, J. Theme and variations: A behavior therapy casebook. New York: Pergamon, 1976.

Wolpe, J., Brady, J. P., Serber M., Agras, W.S., \& Liberman, R. P. The current status of systematic desensitization. American Journal of Psychiatry, 1973, 130, 961-965. 